\title{
Prefilled Applicator Dosage Form
}

National Cancer Institute

\section{Source}

National Cancer Institute. Prefilled Applicator Dosage Form. NCI Thesaurus. Code C91179.

Active and/or inert ing redients in an applicator delivered as a single measured dose. 